\title{
PtAg Alloy Nanoparticles Embedded in Polyaniline as Electrocatalysts for Formate Oxidation and Hydrogen Evolution
}

Meng Huang, Hanyu Zhang, Song Yin, Xiaoxue Zhang, Jun Wang*

Department of Chemistry, College of Science, Northeastern University, Shenyang, Liaoning 110819, China

*Email: wangjun_chem@mail.neu.edu.cn

\section{CONTENT}

S1. Experimental

S1.1. Reagents

S1.2. Instruments

S1.3. Preparation of PtAg Alloy Nanoparticles

S1.4. Preparation of c-PANI@PtAg Nanocomposites

S1.5. Process for Fabricating c-PANI@PtAg/Pt

S1.6. Electrochemical Experiments

S1.7. Pretreatment of Pt Electrode

S2. Results and Discussion

S2.1. Results of EDS, FT-IR and HRTEM Experiments

S2.2. Energy Band Structure

S2.3. TGA Curves

S2.4. Voltammetry Curves of c-PANI@PtAg/Pt

S2.5. Time-Dependent Current Density Curves of c-PANI@PtAg/Pt with Different Mole Ratio of Pt to Ag

S2.6. Electrochemical Studies towards HER in Alkaline Medium

References 


\section{S1. Experimental}

S1.1. Reagents. Aniline was purified by vacuum distillation before used, and other reagents were of analytical grade and unnecessary to be further purified. All solutions were prepared with deionized water. Reagents are listed in Table S1.

Table S1. Chemical reagents

\begin{tabular}{ll}
\hline Molecular formula & Manufacturer \\
\hline $\mathrm{AgNO}_{3}$ & \\
$\mathrm{H}_{2} \mathrm{SO}_{4}$ & Damao Chemical Reagent (Tianjin, China) \\
$\mathrm{CH}_{3} \mathrm{COCH}_{3}$ & \\
$\mathrm{C}_{2} \mathrm{H}_{6} \mathrm{O}$ & \\
$\mathrm{H}_{2} \mathrm{PtCl}_{6} \cdot 6 \mathrm{H}_{2} \mathrm{O}$ & \\
$\left(\mathrm{C}_{6} \mathrm{H}_{9} \mathrm{NO}\right)_{n}(\mathrm{PVP})$ & \\
$\mathrm{C}_{6} \mathrm{H}_{5} \mathrm{NH}_{2}(\mathrm{AN})$ & Sinopharm Chemical Reagent Co., Ltd \\
$\mathrm{CH}_{3} \mathrm{C}_{6} \mathrm{H}_{4} \mathrm{SO}_{3} \mathrm{H}(\mathrm{p}-\mathrm{TSA})$ & \\
$\left(\mathrm{NH}_{4}\right)_{2} \mathrm{~S}_{2} \mathrm{O}_{8}(\mathrm{APS})$ & \\
$\mathrm{HCOONa}$ & \\
$\mathrm{H}_{2} \mathrm{PtCl}_{6} \cdot 6 \mathrm{H}_{2} \mathrm{O}$ & \\
$\mathrm{KOH}$ & Shanghai Chenhua Instrument Company \\
\hline $\mathrm{Al}_{2} \mathrm{O}_{3}$ & Shaanxi Kaida Chemical Engineering Co., Ltd. \\
\hline $\mathrm{PtC}_{(10 \%)}$ & Alfa Aesar (China) Chemical Co., Ltd. \\
\hline $\mathrm{Nafion}(5 \%)$ & \\
\hline
\end{tabular}

S1.2. Instruments. The morphologies, microstructures of the products were characterized by scanning electron microscopy (SEM, Zeiss Ultra Plus), field emission transmission electron microscopy (TEM, FEI Tecnai G2 F20), and high resolution transmission electron microscopy (HRTEM, FEI Tecnai G2 F20). The crystal structures and phase compositions were investigated by X-ray diffraction (XRD, Rigaku D/MAX-3A diffract meter), Fourier-transform infrared spectrum (FT-IR, Nicolet 6700), and UV-Visible spectrum (UV-Vis, Lambda 650S). Thermogravimetric analysis (TGA) curves were obtained by using TGA/DSC3 ${ }^{+}$instrument, Mettler Toledo, Switzerland. The chemical compositions of c-PANI@PtAg and the valence states of each element were carried out by X-ray photoelectron spectroscopy (XPS, Kratos Axis Ultra DLD). All electrochemical properties were tested on an electrochemical workstation (AutoLab PGSTAT 302N, Metrohm, Switzerland).

S1.3. Preparation of PtAg Alloy Nanoparticles. (1) $0.02 \mathrm{~g}$ of PVP was dissolved in $18.0 \mathrm{~mL}$ of distilled water and ultrasonically dispersed for $10.0 \mathrm{~min}$. Dropping $1.0 \mathrm{~mL}$ of $0.039 \mathrm{M} \mathrm{H}_{2} \mathrm{PtCl}_{6}$ 
$6 \mathrm{H}_{2} \mathrm{O}$ and $1.0 \mathrm{~mL}$ of $0.039 \mathrm{M} \mathrm{AgNO}_{3}$ into the mixture and stir well. $0.088 \mathrm{~g} \mathrm{NaBH}_{4}$ was dissolved in $5.0 \mathrm{~mL}$ deionized water then dropwise to the above solution under high-speed stirring. The system was maintained at room temperature for $1.0 \mathrm{~h}$.

(2) After $1.0 \mathrm{~h}$, the product was centrifuged, and in turn washed three times with acetone, ethanol and deionized water, respectively. Product then dried in a vacuum oven at $60{ }^{\circ} \mathrm{C}$ for $3.0 \mathrm{~h}$. The molar ratio of PtAg 0:1, 1:0.5, 1:1, 1:2, 1:0, respectively.

S1.4. Preparation of c-PANI@PtAg Nanocomposites. The synthesis of PtAg alloy nanoparticles was similar to the section 1.3 (1) as above. Then the beaker was placed in an ice-water bath. $1.043 \mathrm{~g}$ of p-TSA was dissolved in and stirring for $10 \mathrm{~min}, 0.5 \mathrm{~mL}$ aniline was added and went on stirring $20 \mathrm{~min}$, and the solution was denoted as (A). At the same time, in another beaker, $1.252 \mathrm{~g}$ of ammonium persulfate was dissolved in $15.0 \mathrm{~mL}$ of deionized water, stirring to dissolve, and the solution was denoted as (B). Then solution (B) was added dropwise to (A) solution in $10 \mathrm{~min}$ with high-speed stirring. After that, slowed down the speed, and kept the system in an ice water bath for $16.0 \mathrm{~h}$. The product was centrifuged and washed three times with acetone, ethanol and water in turn. Finally, the product was dried in a vacuum oven for $3.0 \mathrm{~h}$, and simply expressed as c-PANI@PtAg.

S1.5. Process for Fabricating c-PANI@PtAg/Pt. A Pt electrode was fixed on the inner wall of a beaker before the start of the section S1.3. Then carry out the steps shown in the sections S1.3 (1) and S1.4. After that, the electrode was carefully taken out and in turn soaked in acetone, ethanol and deionized water for $5 \mathrm{~min}$ each. It was then dried in a drying oven at $60{ }^{\circ} \mathrm{C}$ for $3.0 \mathrm{~h}$. The fabricated electrodes are denoted as c-PANI@Pt0Ag1/Pt, c-PANI@Pt1Ag0.5/Pt, c-PANI@Pt1Ag1/Pt, c-PANI@Pt1Ag2/Pt and c-PANI@Pt1Ag0/Pt, respectively.

S1.6. Electrochemical Experiments. Electrochemical tests were carried out a three-electrode system connected with an electrochemical workstation. A saturated calomel electrode (SCE), a Pt sheet and one of the as-fabricated electrode were worked as the reference electrode, the counter electrode and the working electrode, respectively. Cyclic voltammetry (CV), electrochemical impedance spectroscopy (EIS) and chronoamperometry (CA) experiments for FOR were performed in a mixture of $0.1 \mathrm{M} \mathrm{H}_{2} \mathrm{SO}_{4}$ and $2.0 \mathrm{M}$ HCOONa. Linear sweep voltammetry (LSV), Tafel plot and CA experiments for HER were performed in $\mathrm{N}_{2}$-saturated $1.0 \mathrm{M} \mathrm{KOH}$ or $\mathrm{N}_{2}$-saturated $0.1 \mathrm{M} \mathrm{H}_{2} \mathrm{SO}_{4}$ solution. In this paper, the reported FOR potentials are versus SCE electrode ( $v S$. SCE), and HER potentials are versus reversible hydrogen electrode ( $v s$. RHE).

S1.7. Pretreatment of Pt Electrode and PtC/GC Electrode. A Pt sheet electrode (geometric surface area: $1 \mathrm{~cm}^{2}$ ) was polished with grade $1.0,0.3$ and $0.05 \mu \mathrm{m}$ aluminum powder in turn, and 
then it was dipped in a mixed solution of $\mathrm{H}_{2} \mathrm{SO}_{4}$ and $\mathrm{H}_{2} \mathrm{O}_{2}$ (volume ratio was 1:1) for $10 \mathrm{~s}$. After that, the electrode was washed alternately with hot and cold distilled water, and then was dried. The Pt electrode should be polarized alternately at the potential of $1.2 \mathrm{~V}(20 \mathrm{~s})$ and $0.0 \mathrm{~V}(20 \mathrm{~s})$ for $20 \mathrm{~min}$ in $0.5 \mathrm{~mol} \cdot \mathrm{L}^{-1} \mathrm{H}_{2} \mathrm{SO}_{4}$ aqueous solution. ${ }^{\mathrm{S} 1}$ Electrochemical active surface area of the $\mathrm{Pt}$ electrode $\left(1.17 \mathrm{~cm}^{2}\right)$ was measured by cyclic voltammetry.

Commercial PtC powder is mixed with nafion solution and coating on a glass carbon electrode $(\mathrm{PtC} / \mathrm{GC})$. The way of processing $\mathrm{PtC}$ powder may refer to the reference S2.

\section{S2. Results and Discussion}

S2.1. Characterization. Figure S1a and 1b show the EDS of c-PANI@PtAg and FT-IR spectra of c-PANI and c-PANI@PtAg. Attributions of FT-IR absorption peaks of c-PANI@PtAg are shown in Table S2. Compared with those of c-PANI, the absorption peaks of c-PANI@PtAg show just slightly shift. Figure S1c shows that the size of PtAg alloy nanoparticles is about $3 \mathrm{~nm}$.
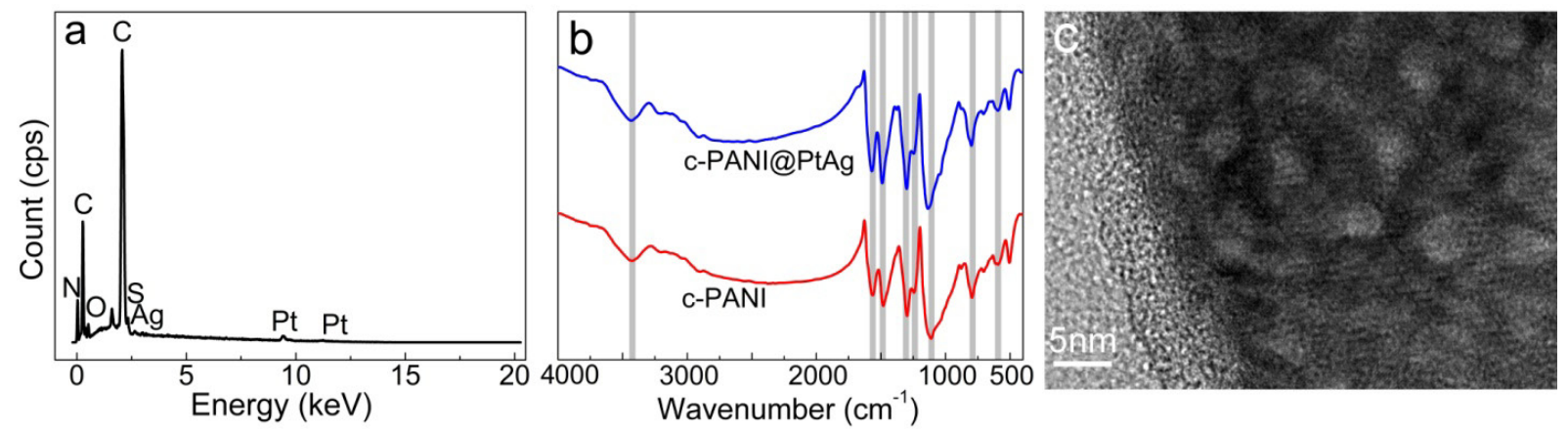

Figure S1. (a) EDS of c-PANI@PtAg, (b) FT-IR of c-PANI@PtAg and c-PANI, (c) HRTEM images of c-PANI@PtAg.

Table S2. Attributions of characteristic peaks on the FT-IR spectrum of c-PANI@PtAg

\begin{tabular}{cl}
\hline Wave number $\left[\mathrm{cm}^{-1}\right]$ & \multicolumn{1}{c}{ Mode of vibration } \\
\hline 513 and 853 & out-of-plane deformation of aromatic ring $\mathrm{C}-\mathrm{H}$ \\
1128 & protonated PANI characteristic absorption \\
1296 and 1242 & stretching vibration of $\mathrm{C}-\mathrm{N}$ on benzene ring \\
1575 & quinoid ring type $\mathrm{C}=\mathrm{C}$ stretching vibration \\
1499 & benzene ring type $\mathrm{C}=\mathrm{C}$ stretching vibration \\
\hline
\end{tabular}

S2.2. Energy Band Structure. UV-Vis spectra of c-PANI, c-PANI@PtAg (Figure S2a) show two typical absorption bands of c-PANI around 345 and $630 \mathrm{~nm}$ corresponding to $\pi \rightarrow \pi^{*}$ electron conversion and $n \rightarrow \pi^{*}$ electron change of phenyl ring to fluorene ring. The relationship between 
the organic band gap $E_{\mathrm{g}}$ and $\lambda_{\max }$ is shown as Eq. S2.1. ${ }^{\mathrm{S} 3}$ Here, $\lambda_{\max }$, the wavelength of the absorption band edge, of c-PANI and c-PANI@PtAg are 774.3 and 794.2 nm, respectively.

$$
E_{\mathrm{g}}=h c / \lambda_{\max }
$$

$\mathrm{CV}$ curves of c-PANI/Pt and c-PANI/PtAg/Pt in $0.1 \mathrm{~mol} \cdot \mathrm{L}^{-1} \mathrm{H}_{2} \mathrm{SO}_{4}$ (Figure $\mathrm{S} 2 \mathrm{~b}$ ) show two pairs of peak $\mathrm{O} 1 / \mathrm{R} 1$ and $\mathrm{O} 2 / \mathrm{R} 2$, corresponding to the redox of c-PANI among oxidation state, partial oxidation state and reduction state, respectively. The relationship among $E_{\mathrm{O}}, E_{\mathrm{R}}$ and half-wave potential $e E_{1 / 2}$ can be expressed as Eq. S2.2. ${ }^{\mathrm{S} 4}$ The relationship between the energy level of the highest occupied molecular orbital $\left(E_{\mathrm{HOMO}}\right)$ and $e E_{1 / 2}$ can be expressed as Eq. S2.3.

$$
\begin{aligned}
& e E_{1 / 2}=e\left(E_{\mathrm{O}, 1}+E_{\mathrm{R}, 1}\right) / 2 \\
& E_{\mathrm{HOMO}}=-\left|e E_{1 / 2}+4.5 \mathrm{eV}+E_{\mathrm{SCE}}\right|
\end{aligned}
$$

$E_{\mathrm{SCE}}=0.24 \mathrm{eV}$. The lowest unoccupied molecular orbital energy ( $\left.E_{\mathrm{LUMO}}\right)$ is calculated by Eq. S2.4. Table S3 lists the $E_{\mathrm{HOMO}}$ and $E_{\mathrm{LUMO}}$ values of c-PANI and c-PANI@PtAg.

$$
E_{\mathrm{LUMO}}=E_{\mathrm{HOMO}}+E_{\mathrm{g}}
$$
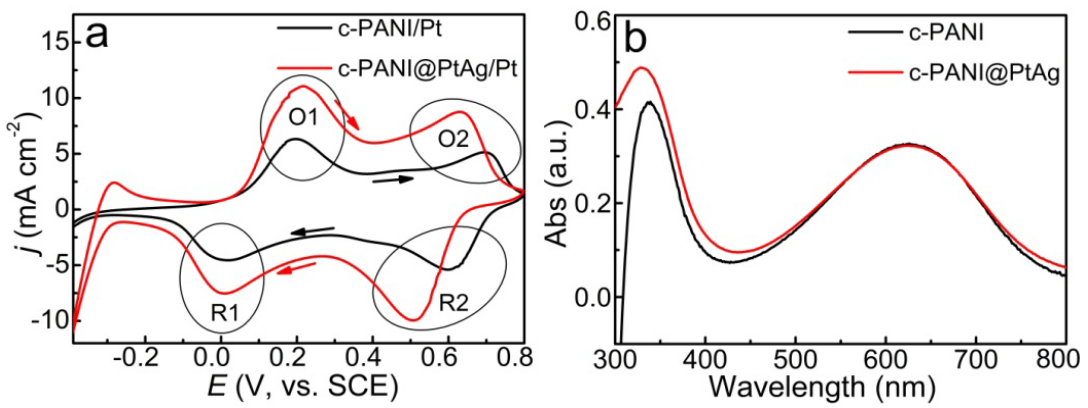

Figure S2. c-PANI/Pt and c-PANI/PtAg/Pt electrodes: (a) CV curves in $0.1 \mathrm{M} \mathrm{H}_{2} \mathrm{SO}_{4}$, scanning rate: $50 \mathrm{mV} \cdot \mathrm{s}^{-1}$; (b) UV-Vis spectrum in $\mathrm{N}, \mathrm{N}$-dimethyl formamide solution.

Table S3. Energy level of c-PANI and c-PANI@PtAg

\begin{tabular}{llc}
\hline Energy level $[\mathrm{eV}]$ & $\mathrm{c}-\mathrm{PANI}$ & $\mathrm{c}-\mathrm{PANI} @ \mathrm{PtAg}$ \\
\hline$E_{\mathrm{g}}$ & 1.60 & 1.56 \\
$E_{\mathrm{HOMO}, \mathrm{O} / \mathrm{R} 1}$ & -4.85 & -4.85 \\
$E_{\mathrm{HOMO}, \mathrm{O} / \mathrm{R} 2}$ & -5.30 & -5.31 \\
$E_{\mathrm{LUMO}} \mathrm{O} / \mathrm{R} 1$ & -3.25 & -3.29 \\
$E_{\mathrm{LUMO}, \mathrm{O} / \mathrm{R} 2}$ & -3.70 & -3.75 \\
\hline
\end{tabular}

S2.3. TGA Curves. Each of the curves (Figure S3) shows a lost weight below $100^{\circ} \mathrm{C}$ because of dehydration. However, the bigger slope of the curve of c-PANI@PtAg indicates a more regular structure. The second weight loss around $300^{\circ} \mathrm{C}$ and the third weight loss in the range of $300-500^{\circ} \mathrm{C}$ are due to proton-dedoping and degradation of c-PANI chains, respectively. In 
contrast, collapsing rate of the c-PANI@PtAg molecular chains is significantly lower than that of c-PANI, suggesting PtAg nanoparticles to be conducive to the thermal stability of c-PANI.

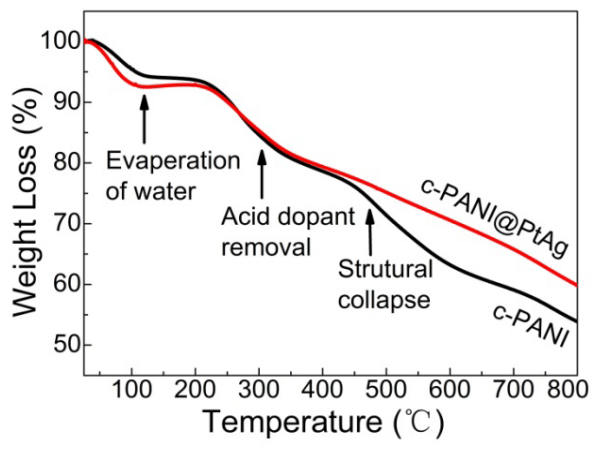

Figure S3. TGA curves of c-PANI@PtAg and c-PANI.

S2.4. Voltammetry Curves of c-PANI@PtAg/Pt. Figure S4 indicates that the c-PANI@Pt1Ag2/Pt presents the highest oxidation peak current density for HCOOH-HCOO'. The peak area ratio of positive sweep to negative sweep $\left(S_{\mathrm{p}} / S_{\mathrm{n}}\right)$ of c-PANI@Pt1Ag0.5/Pt, c-PANI@Pt1Ag1/Pt and c-PANI@Pt1Ag2/Pt equal to 1.6, 1.1 and 1.1, respectively. The closer the ratio is to 1 , the stronger the resistance to $\mathrm{CO}$-poisoning. The ratio of $\mathrm{PtC} / \mathrm{GC}$ is 0.59 , indicating a serious CO-poisoning during catalyzing FOR.
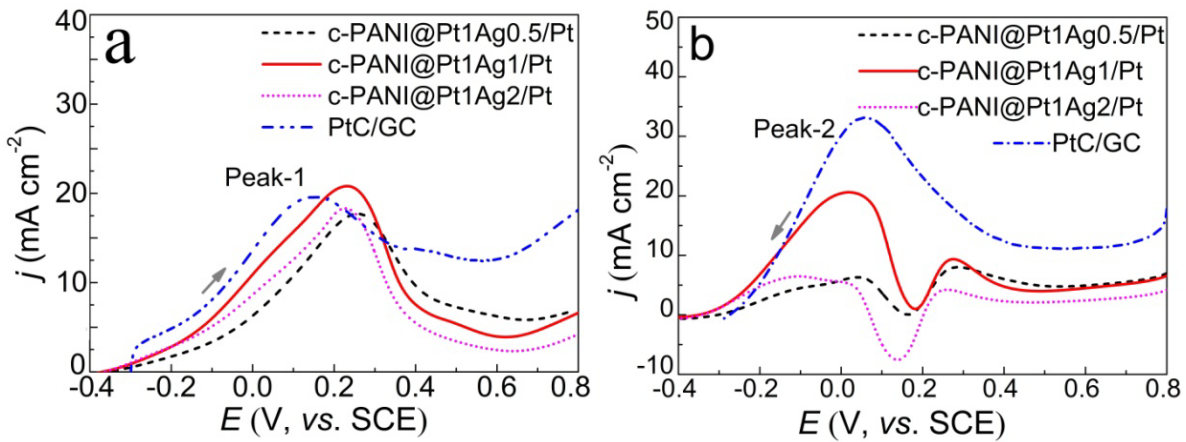

Figure S4. (a) Positive and (b) negative sweep voltammetry curves of c-PANI@PtAg/Pt and $\mathrm{PtC} / \mathrm{GC}$ in a mixture of $0.1 \mathrm{M} \mathrm{H}_{2} \mathrm{SO}_{4}$ and $2.0 \mathrm{M} \mathrm{HCOONa}$, scanning rate: $50 \mathrm{mV} \cdot \mathrm{s}^{-1}$, the mole ratio of $\mathrm{Pt}$ to $\mathrm{Ag}$ adopted in the electrode is $1: 0.5,1: 1$ and 1:2, respectively.

\section{S2.5. Time-Dependent Current Density Curves of c-PANI@PtAg/Pt with Different}

Pt-to-Ag Ratio. The time-dependent current density curves of c-PANI@PtAg/Pt with different mole ratio of $\mathrm{Pt}$ to $\mathrm{Ag}$ (Figure S5) shows that, when the ratio is 1:0.5 or 1:1, the curve occurs a platform at about $500 \mathrm{~s}$, and then the current density changes little. But, for the c-PANI@Pt1Ag2/Pt, the current density decreases obviously before 3000 s. 


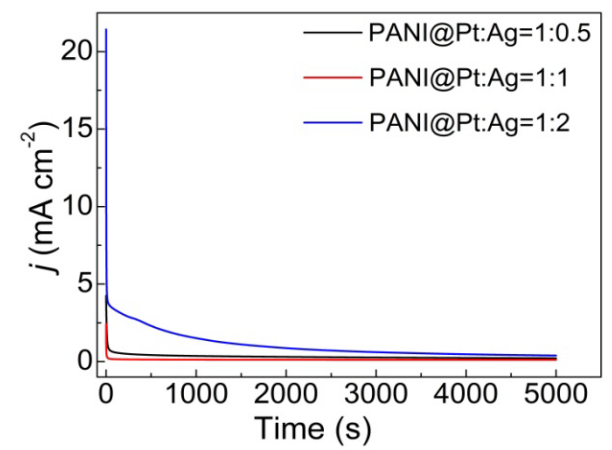

Figure S5. CA curves of c-PANI@PtAg/Pt with different mole ratio of Pt to Ag in a mixture of $0.1 \mathrm{M} \mathrm{H}_{2} \mathrm{SO}_{4}$ and $2.0 \mathrm{M} \mathrm{HCOONa}$.

S2.6. Electrochemical Studies towards HER in Alkaline Medium. Figure S6 shows that, in an alkaline medium, the overpotentials of c-PANI@PtAg/Pt with the Pt-to-Ag ratio of 1:0.5, 1:1 and 1:2, and Pt are $-22,-31,-31$ and $-24 \mathrm{mV}$, and the Tafel slopes of the four electrodes are 83, 97,88 and $66 \mathrm{mV} \mathrm{dec}^{-1}$, respectively.
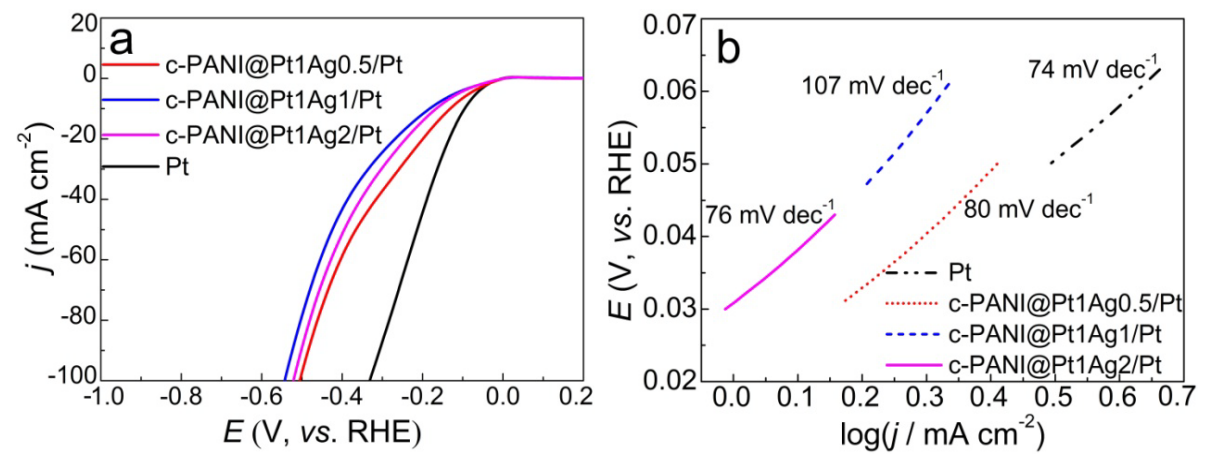

Figure S6. (a) Linear sweep voltammetry curves and (b) Tafel curves of c-PANI@PtAg/Pt with different Pt-to-Ag ratio and $\mathrm{Pt}$ in $1.0 \mathrm{M} \mathrm{NaOH}$ solution. Scanning rate: $5 \mathrm{mV} \mathrm{s}^{-1}$.

\section{- References}

(S1)Wang, J.; Ning, Y.; Wen, Y.; Wen, Y.; Dong, T.; Wang, D.; Chen, M.; Zhang, L. Characteristics and Electrochemical Reaction Kinetics of Polyaniline Nanofibers as a Promoter of Pt Electrode for Methanol Electrocatalytic Oxidation. Z. Phys. Chem. 2013, 227, 89-103.

(S2)Schmidt, T. J.; Gasteiger, H. A.; Stab, G. D.; Urban, P. M.; Kolb, D. M.; Behm, R. J. Characterization of High-Surface Area Electrocatalysts Using a Rotating Disk Electrode Configuration. J. Electrochem. Soc. 1998, 145, 2354-2358.

(S3) Yang, Z. Y.; Wang, Y. E.; Dong, T.; Yuan, X. F.; Lv, L. L.; Wei, X. B.; Wang, J. Formate: A Possible Replacement for Formic Acid in Fuel Cells. Aust. J. Chem. 2017, 70, 757-763. 
(S4)Aguilar-Martinez, M.; Cuevas, G.; Jimenez-Estrada, M.; González, I.; Lotina-Hennsen, B.; Macias-Ruvalcaba, N. An Experimental and Theoretical Study of the Substituent Effects on the Redox Properties of 2-[(r-Phenyl)Amine]-1,4-Naphthalenediones in Acetonitrile. J. Org. Chem. 1999, 64, 3684-3694. 